\title{
ALTERAÇÕES ELETROQUÍMICAS DE UM LATOSSOLO VERMELHO-AMARELO TRATADO COM CARBONATO E SULFATO DE CÁLCIO ${ }^{1}$
}

\author{
Paulo Guilherme S. Wadt ${ }^{2}$ \\ ${ }^{2}$ Meta Agroflorestal, C.P. 224 - CEP: $13730-970$ - Mococa, SP \\ Autor correspondente <pgswadt@osite.com.br>
}

\begin{abstract}
RESUMO: Amostras de um Latossolo Vermelho-Amarelo, argiloso, coletadas do horizonte A e Bw de solo sob floresta e pastagem foram utilizadas no estudo da movimentação de cátion. As amostras dos solos A-floresta e A-pastagem foram tratadas com carbonato de cálcio, sulfato de cálcio ou com a mistura destas fontes de cálcio, com o propósito de avaliar seus efeitos sobre as principais reações eletroquímicas do solo, principalmente em relação à adição de sulfato. A seguir, as amostras foram colocadas em potes sobre as amostras Bw. Após a incubação, foram lixiviadas com sete volume-poros de água destilada, em aplicações semanais. Terminado o período de lixiviação, procedeu-se à análise de cálcio, magnésio, potássio, e alumínio trocáveis, pH em água, $\mathrm{pH}$ em KCl $1 \mathrm{~mol} \mathrm{~L}^{-1}$, acidez potencial e determinação do ponto de efeito salino nulo (PESN). Nas amostras superficiais, a aplicação de sulfato resultou em diminuições do teor de alumínio trocável, sem alterar a CTC-efetiva, a CTC a pH 7,0, o PESN, sendo a principal reação do sulfato provavelmente sua precipitação com o alumínio. Nas amostras subsuperficiais, a aplicação de sulfato de cálcio resultou em alterações no PESN, CTC-efetiva e CTC a pH 7,0, sem diminuir os teores de alumínio trocável, sendo que a principal reação do sulfato com o solo foi, provavelmente, de adsorção química. A aplicação isolada de carbonato de cálcio neutralizou a acidez, em todos os seus componentes, de forma mais eficiente que os demais tratamentos, sendo que a mistura das duas fontes de cálcio proporcionou alterações na acidez do solo comparáveis à aplicação isolada de carbonato de cálcio.
\end{abstract}

Palavras-chave: adsorção, ponto de carga zero, efeito salino, gesso agrícola

\section{ELECTROCHEMICAL CHANGES OF AN OXISOL DUE TO CALCIUM CARBONATE AND SULPHATE APPLICATIONS}

\begin{abstract}
Soil samples of an Oxisol collected from the soil A horizon under forest or grassland, and the oxic horizon (B) were used for the study of cation movement. The A-forest and A-grassland samples were treated with calcium carbonate, calcium sulphate or with a combination of both, with the objetive of evaluating the electrochemical changes of the soil, mainly in relation to the sulphate. Afterwards, the A horizon samples were packed in pots over the B horizon samples and incubated. After incubation the samples were leached with seven pore-volumes of destilled water, weekly. After this, exchangeable calcium, magnesium, potassium and aluminium, $\mathrm{pH}$ in water, $\mathrm{pH}$ in $1 \mathrm{~mol} \mathrm{~L}^{-1} \mathrm{KCl}$, potencial acidity and the zero point of salt effect (ZPSE) were evaluated. With sulphate application the $\mathrm{A}$ horizon presented a decrease in exchangeable aluminium, without changes in the effective CEC, CEC at pH 7.0, and ZPSE. Sulphate was probably precipitated by aluminum. In relation to the $B$ horizon, sulphate application resulted in alterations of the ZPSE, effective CEC and CEC at $\mathrm{pH}$ 7.0, without a decrease in the exchangeable aluminum. In this layer, chemical adsorption of sulphate might wave occurred. Calcium carbonate was more efficienty in decreasing soil acidity. The combination of carbonate with calcium sulphate was similar to the addition of carbonate only in the decrease of soil acidity.

Key words: adsorption, zero point of charge, saline effect, gypsum
\end{abstract}

\section{INTRODUÇÃO}

A adsorção de sulfato pelo solo tem sido considerada um dos principais processos responsáveis pela sua disponibilidade na solução do solo. Foi observado que carbonato de cálcio diminui o número de sítios disponíveis para a adsorção de sulfato, enquanto que a adição de fosfato diminui tanto o número de sítios disponíveis quanto a força de adsorção (Bolan et al., 1988). Portanto, a adição dos ânions carbonato ou fosfato favoreceria a movimentação do sulfato no solo, por diminuir-lhe a retenção (Motavalli et al., 1993).
Assim, a capacidade do solo em remover sulfato da solução, e portanto, diminuir as perdas deste elemento por lixiviação, depende de sua inerente propriedade de adsorção (a qual pode ser afetada pela adsorção de outros íons), do nível de adsorção prévia de sulfato e da concentração deste na solução que percola em relação à concentração da solução com a qual o solo foi anteriormente equilibrado (Nodvin et al., 1986b)

Lobo (1986) observou que quando sulfato esteve presente em baixas concentrações, este foi adsorvido mais próximo da superfície, causando abaixamento do PESN (ponto de efeito salino nulo), enquanto que a altas

${ }^{1}$ Parte da Tese de Mestrado do autor apresentada à UFRRJ - Itaguaí, RJ. 
concentrações foi adsorvido na camada de Stern, resultando numa elevação do PESN. Por outro lado, Bolan et al. (1986) não observaram nenhum efeito da adição de sulfato sobre o PESN, indicando que sulfato não seria adsorvido especificamente. Outro possível mecanismo consiste na "adsorção salina", processo pelo qual o sulfato, tendo como principal íon acompanhante o cálcio, seria adsorvido eletrostaticamente pelas superfícies coloidais do solo na forma de par iônico (Pearce \& Sumner, 1997).

Por outro lado, Marsh et al. (1987) consideram que a ligação entre o sulfato e a superfície tem um grande componente eletrostático na ligação, com pouca adsorção ocorrendo na ausência de cargas positivas; no entanto, a ligação não é inteiramente não-específica, pois os autores observaram forte seletividade para adsorção de sulfato sobre ânions adsorvidos não-especificamente (cloreto, por exemplo). Segundo estes autores, este comportamento seria consistente com a hipótese de que a adsorção de sulfato ocorre num plano o qual seria mais próximo da superfície que o plano de adsorção não-específica, porém, claramente distinto da superfície, ou seja, na camada de Stern. Este mecanismo seria consistente com resultados que apontam que a adsorção de sulfato seria diminuída pela adição de materiais orgânicos ao solo (Motavalli et al., 1993), notadamente daqueles com maior relação C/ $\mathrm{N}$, de mais difícil decomposição, que ao formarem compostos húmicos, competiriam com o sulfato pelos sítios de adsorção.

Além dos mecanismos de adsorção, o desaparecimento do sulfato da solução do solo pode darse por meio de reações de precipitação, principalmente com sulfatos básicos de alumínio (Yamada, 1988). A precipitação dos íons sulfato formando basuluminita $\left(\mathrm{Al}_{4}(\mathrm{OH})_{10} \mathrm{SO}_{4}\right)$ e alunita $\left(\mathrm{KAl}_{3}(\mathrm{OH})_{6}\left(\mathrm{SO}_{4}\right)_{2}\right)$ foi proposta inicialmente por Adams \& Rawajfih (1977) como um processo envolvido no desaparecimento do sulfato da fase solúvel.

Evans Junior \& Zelazny (1987) observaram em lixiviado de solos que a solução percolada foi supersaturada com relação a basuluminita e alunita, em tratamentos que continham COD (carbono orgânico dissolvido); aumentos da concentração de sulfato na solução adicionada resultaram em diminuições da concentração de alumínio livre e sulfato no lixiviado, e de alumínio trocável nos solos, sugerindo remoção de ambas as espécies por precipitação. Por sua vez, Curtin \& Syers (1990) não observaram condições, a partir do valor do produto de atividade iônica dos íons sulfato, alumínio e prótons, que indicassem precipitação de sulfato formando basuluminita ou alunita.

As reduções no teor de alumínio trocável com a adição de gesso, observadas por inúmeros autores (Chaves et al., 1988; Pavan et al., 1984; Sumner et al., 1986), poderiam então estar relacionadas à precipitação do alumínio com o sulfato. Neste caso, a presença do ânion sulfato dificultaria o processo de lixiviação do $\mathrm{Al}^{3+}$.
A aplicação de sulfato de cálcio ao solo poderia também impedir a movimentação do alumínio por meio da imobilização deste em reações de neutralização. Ritchey et al. (1980) consideram que a liberação de hidroxilas causada pela adsorção de sulfato promoveria a neutralização de parte do alumínio trocável. Conseqüentemente, este passaria para uma fase imóvel, indisponível para lixiviar.

Estes mecanismos foram propostos para explicar a diminuição do teor de alumínio trocável em função da aplicação do gesso agrícola. Neste mesmo sentido, Saigussa \& Toma (1997) propuseram o seguinte mecanismo para explicar a redução do alumínio trocável: primeiramente, o $\mathrm{Al}^{3+}$ trocável adsorvido nos sítios de troca seria liberado na solução do solo em decorrência do aumento da força iônica causada pela aplicação do gesso e, após, os monômeros de $\mathrm{Al}^{3+}$ presentes na solução seriam polimerizados na presença dos colóides do solo. Finalmente, estes polímeros de alumínio seriam seletivamente e irreversivelmente fixados nos sítios de troca catiônica.

Portanto, as reações envolvendo tanto a adsorção do sulfato, quanto a precipitação do alumínio no solo, poderiam levar a processos que diminuem a disponibilidade de sulfato para lixiviar, afetando assim a movimentação dos cátions acompanhantes.

O presente trabalho teve por objetivo verificar os efeitos da adição de carbonato e sulfato de cálcio sobre as propriedades eletroquímicas do solo, principalmente no que se refere às reações envolvendo o sulfato.

\section{MATERIAL E MÉTODOS}

Amostras superficiais $(0$ a $5 \mathrm{~cm}$ ) de um Latossolo Vermelho-Amarelo, argiloso, álico, do munícipio de Piraí (RJ), coletadas sob vegetação de pastagem nativa, Paspalum notatum $L$, e sob floresta secundária (amostras A-pastagem e A-floresta, respectivamente), foram peneiradas e misturadas com fontes de cálcio e colocadas a incubar em potes plásticos de $1.800 \mathrm{~cm}^{3}$, sobre amostras coletadas no horizonte Bw (200 a $250 \mathrm{~cm}$ de profundidade), da mesma unidade de solo, em barranco de estrada, após remoção da parte mais externa e exposta à atmosfera livre (TABELA 1). Na montagem dos potes foram utilizados 1.000 gramas da amostra de subsuperfície (B) e 750 gramas das amostras de superfície (A-floresta ou A-pastagem), por pote, além de um volume de $70 \mathrm{~cm}^{3}$ de areia lavada que foi colocada entre as duas amostras, para facilitar a posterior separação destas. As amostras superficiais e subsuperficiais foram colocadas em porções de 150 gramas e compactados para uma densidade de $1,25 \mathrm{Mg} \mathrm{m}^{-3}$, aplicando-se a mesma compactação em ambas as profundidades. Neste trabalho, a camada superficial será considerada aquela que recebeu diretamente os tratamentos, e a camada subsuperficial aquela disposta abaixo da camada que recebeu os tratamentos. Adota-se o termo "camada" pelo fato de essas amostras não representarem todo o corpo morfogenético dos horizontes de que foram retiradas. 
TABELA 1 - Caracterização química e física de amostras de um Latossolo Vermelho-Amarelo do município de Pirai $(\mathrm{RJ})$, sob diferentes coberturas vegetais.

\begin{tabular}{lccc}
\hline Características: & A-pastage m & A-floresta & Bw \\
\hline profundidade $(\mathrm{cm})$ & 0 a 5 & 0 a 5 & 200 a 250 \\
pH em água & 4,70 & 4,20 & 5,00 \\
$\mathrm{pH} \mathrm{em} \mathrm{KCl} \mathrm{1} \mathrm{mol} \mathrm{L-1}$ & 4,00 & 3,80 & 4,50 \\
$\mathrm{Ca}^{+2}\left(\mathrm{cmol}_{(+)} \mathrm{kg}^{-1}\right)$ & 0,40 & 0,35 & 0,13 \\
$\mathrm{Mg}^{+2}\left(\mathrm{cmol}_{(+)} \mathrm{kg}^{-1}\right)$ & 0,25 & 0,30 & 0,12 \\
$\mathrm{~K}^{+}\left(\mathrm{cmol}_{(+)} \mathrm{kg}^{-1}\right)$ & 0,15 & 0,14 & 0,03 \\
$\mathrm{Na}^{+}\left(\mathrm{cmol}_{(+)} \mathrm{kg}^{-1}\right)$ & 0,04 & 0,05 & 0,01 \\
$\mathrm{Al}^{+3}\left(\mathrm{cmol}_{(+)} \mathrm{kg}^{-1}\right)$ & 1,05 & 1,43 & 0,23 \\
$\mathrm{Al}^{+3}+\mathrm{H}^{+}\left(\mathrm{cmol}_{(+)} \mathrm{kg}^{-1}\right)$ & 5,80 & 7,50 & 2,50 \\
$\mathrm{carbono}_{\left(\mathrm{g} \mathrm{kg}^{-1}\right)}$ & 18,0 & 25,0 & 2,00 \\
argila $\left(\mathrm{g} \mathrm{kg}^{-1}\right)$ & 400 & 350 & 600 \\
equiv.umidade & 350 & 360 & 390 \\
(g kg-1) & 2,45 & 2,38 & 2,29 \\
dens. real $\left(\mathrm{Mg} \mathrm{m}^{-3}\right)$ & & &
\end{tabular}

Os tratamentos aplicados nas amostras superficiais de cada solo foram:

(a) testemunha, sem aplicação de cálcio;

(b) aplicação isolada de carbonato de cálcio, equivalendo a $3,2 \mathrm{~g}$ de $\mathrm{CaCO}_{3} \mathrm{~kg}^{-1}$ de solo;

(c) aplicação isolada de sulfato de cálcio, equivalendo a $5,5 \mathrm{~g}$ de $\mathrm{CaSO}_{4} \cdot 2 \mathrm{H}_{2} \mathrm{O} \mathrm{kg}^{-1}$ de solo e;

(d) mistura das duas fontes de cálcio, com $2 / 3$ do cálcio aplicado na forma de carbonato de cálcio e 1/3 na forma de sulfato de cálcio.

A dose de carbonato de cálcio no tratamento "b" foi determinada por meio de experimento prévio de incubação, sendo a dose escolhida aquela que foi suficiente para elevar o $\mathrm{pH}$ do solo a valores em torno de 6,0 a 6,5 . As doses dos outros tratamentos foram calculadas de forma a se aplicar a mesma quantidade de centimols de cálcio. $O$ delineamento experimental adotado foi o inteiramente casualizado, com três repetições.

Findo o período de incubação (48 dias), os potes foram lixiviados com cerca de $4.718 \mathrm{~cm}^{3}$ de água destilada por pote, volume este equivalente a aproximadamente sete vezes o volume-poro ${ }^{3}$. A aplicação de água foi a uma taxa média de 1,9 $\pm 0,7 \mathrm{~cm}^{3} \mathrm{~min}^{-1}$, sendo que foi aplicado aproximadamente um volume-poro por semana.

Após o período de lixiviação, a camada superficial (camada A) foi retirada e na amostra subsuperficial procedeu-se a teste biológico de crescimento da raiz primária de plântula de sorgo. Terminado o teste, a amostra subsuperficial de cada repetição experimental foi também retirada e levada à sucção com bomba de vácuo, para retirada da solução do solo. A seguir, foi colocada a secar à semelhança da amostra superficial (camada A).
As amostras, das respectivas profundidades, foram analisadas com relação a pH em $\mathrm{H}_{2} \mathrm{O}$, alumínio, cálcio e magnésio trocáveis em $\mathrm{KCl} 1,0 \mathrm{M}$ e potássio extraído com solução diluída de ácidos fortes (North Carolina) (Raij et al., 1987; Empresa Brasileira de Pesquisa Agropecuária, 1979) e acidez potencial a pH 7,0 (Empresa Brasileira de Pesquisa Agropecuária, 1979). Com os valores de soma de cátions trocáveis determinou-se a CTC efetiva (CTC-ef) e, com a soma de acidez potencial + cátions alcalinos e alcalinos terrosos trocáveis (CAAT trocáveis), determinou-se a CTC a pH 7,0 (CTC). Nas amostras de ambas as profundidades foi determinado o ponto de efeito salino nulo (PESN), segundo Uehara \& Gillman (1981), com ligeiras modificações no procedimento (Wadt, 1991), descrito na integra por Wadt et al. (1995).

A análise estatística foi feita comparando-se as médias de cada tratamento por meio do teste de Duncan a $5 \%$.

\section{RESULTADOS E DISCUSSÃO}

Todos os tratamentos com aplicação de fontes de cálcio foram efetivos em aumentar o pH em água, tanto na superfície quanto na subsuperfície, à exceção da aplicação isolada de sulfato de cálcio que não logrou aumentar o pH em água na superfície, para a amostra "Apastagem" (TABELAS 2 e 3 ).

$\mathrm{Na}$ camada superficial, aumentos na CTC a pH 7,0 ocorreram nos tratamentos com aplicação com carbonato de cálcio nas amostras sob pastagem e no tratamento com aplicação isolada de sulfato de cálcio nas amostras sob floresta; enquanto que na subsuperfície, invariavelmente, os aumentos da CTC estiveram relacionados à aplicação de sulfato de cálcio, seja isoladamente ou não. Paralelamente, observaram-se aumentos da CTC efetiva (soma de CAAT trocáveis mais alumínio trocável) em ambas as profundidades.

Na superfície, este aumento da CTC efetiva esteve intimamente relacionado aos aumentos do $\mathrm{pH}$ do solo e à liberação de sítios de troca originalmente ocupados por hidrogênio e/ou alumínio, tendo este processo resultado da possível precipitação do alumínio e na diminuição da acidez ativa, da acidez trocável e da acidez potencial, nos tratamentos com aplicação de carbonato de cálcio (TABELA 2).

No entanto, na subsuperfície os aumentos da CTC efetiva não estiveram relacionados à liberação de sítios de troca originalmente ocupados por hidrogênio e/ou alumínio, pois, nestes os aumentos da CTC efetiva ocorreram independentemente de aumentos no $\mathrm{pH}$. Assim, os aumentos na CTC efetiva podem ser atribuídos à geração de novos sítios de adsorção de cátions, uma vez que a maior CTC efetiva não se deu em detrimento da acidez potencial.

\footnotetext{
${ }^{3}$ volume equivalente a porosidade total de cada camada, calculado com base na densidade real das partículas dos solos e da densidade aparente destes dentro de cada pote. A porosidade total foi calculada como sendo de $49 \%, 47 \%$ e $45 \%$, para as amostras subsuperficiais (B), e superficiais (A-floresta e A-pastagem), respectivamente.
} 
TABELA 2 - Valores médios de pH em água, alumínio trocável, CTC, CTC-ef e, PESN, em amostras superficiais de um (0 a $5 \mathrm{~cm}$ de profundidade) de um Latossolo Vermelho-Amarelo do município de Pirai (RJ), sob dois tipos de vegetação (floresta e pastagem), incubadas com diferentes fontes de cálcio.

\begin{tabular}{|c|c|c|c|c|c|}
\hline \multirow[t]{2}{*}{ Tratamentos ${ }^{1}$} & \multirow[t]{2}{*}{$\mathrm{pH}$} & $\mathrm{Al}^{3+}$ & СТC & CTC-ef & \multirow[t]{2}{*}{ PESN } \\
\hline & & \multicolumn{3}{|c|}{--- $\mathrm{cmol}_{(+)} \mathrm{kg}^{-1}$ solo ---- } & \\
\hline & \multicolumn{5}{|c|}{ LV sob pastage m } \\
\hline testemunha & $4,59 \mathrm{e}$ & $1,23 \mathrm{~b}$ & $5,95 d$ & $1,88 \mathrm{~d}$ & $3,1 \mathrm{a}$ \\
\hline $\begin{array}{l}\text { carbonato } \\
\text { isolado }\end{array}$ & $6,29 a$ & $0,01 \mathrm{e}$ & $6,65 \mathrm{c}$ & $4,61 \mathrm{a}$ & $3,4 a$ \\
\hline $\begin{array}{l}\text { sulfato } \\
\text { isolado }\end{array}$ & 4,68 e & $0,65 \mathrm{c}$ & $6,31 \mathrm{~cd}$ & $2,18 d$ & $3,2 \mathrm{a}$ \\
\hline \multirow[t]{2}{*}{$\begin{array}{l}\text { carbonato e } \\
\text { sulfato }\end{array}$} & $5,84 \mathrm{~b}$ & 0,03 e & $6,68 \mathrm{c}$ & $3,88 b$ & $3,2 \mathrm{a}$ \\
\hline & \multicolumn{5}{|c|}{ LV sob floresta } \\
\hline testemunha & $4,12 \mathrm{~g}$ & $1,92 \mathrm{a}$ & $7,95 b$ & $2,57 c$ & $3,0 \mathrm{a}$ \\
\hline $\begin{array}{l}\text { carbo nato } \\
\text { isolado }\end{array}$ & $5,51 \mathrm{c}$ & $0,07 \mathrm{e}$ & $8,35 a b$ & $4,57 \mathrm{a}$ & $3,1 \mathrm{a}$ \\
\hline $\begin{array}{l}\text { sulfato } \\
\text { isolado }\end{array}$ & $4,30 \mathrm{f}$ & $1,28 b$ & $8,74 \mathrm{a}$ & $2,62 \mathrm{c}$ & $2,8 a$ \\
\hline $\begin{array}{l}\text { carbonato e } \\
\text { sulfato }\end{array}$ & $4,93 \mathrm{~d}$ & $0,20 d$ & $8,39 a b$ & $3,51 \mathrm{~b}$ & $3,2 \mathrm{a}$ \\
\hline
\end{tabular}

${ }^{(1)}$ médias seguidas de mesma letra, dentro da mesma coluna, não diferem pelo teste de Duncan a $5 \%$.

TABELA 3 - Valores de pH em água, alumínio trocável, CTC, CTC-efetiva (CTC-ef), Calcio trocável $\left(\mathrm{Ca}^{+2}\right)$ e, PESN, em amostras subsuperficiais do horizonte Bw de um Latossolo Vermelho-Amarelo do município de Pirai (RJ), à profundidade de 200 a $250 \mathrm{~cm}$, dispostas em potes sob solos (pastagem e floresta) incubados com diferentes fontes de cálcio.

\begin{tabular}{|c|c|c|c|c|c|}
\hline \multirow[t]{2}{*}{ Tratamento $^{1}$} & \multirow[t]{2}{*}{$\mathrm{pH}$} & CTC & CTC-ef & $\mathrm{Ca}^{+2}$ & \multirow[t]{2}{*}{ PESN } \\
\hline & & \multicolumn{3}{|c|}{$\mathrm{cmol}_{(+)} \mathrm{kg}^{-1}$ solo } & \\
\hline & \multicolumn{5}{|c|}{ LV sob pastagem } \\
\hline testemunha & $4,62 d$ & $0,28 a b 2,78 c$ & $0,59 d$ & $0,13 \mathrm{c}$ & $5,20 a$ \\
\hline $\begin{array}{l}\text { carbonato } \\
\text { isolado }\end{array}$ & $4,94 \mathrm{a}$ & $0,14 \mathrm{~d} \quad 2,86 \mathrm{c}$ & $0,86 \mathrm{c}$ & $0,54 \mathrm{~b}$ & $5,08 \mathrm{ab}$ \\
\hline $\begin{array}{l}\text { sulfato } \\
\text { isolado }\end{array}$ & $4,81 \mathrm{bc}$ & $0,26 \mathrm{~b} \quad 3,52 \mathrm{a}$ & $1,50 \mathrm{a}$ & $1,13 \mathrm{a}$ & $4,53 \mathrm{c}$ \\
\hline \multirow[t]{2}{*}{$\begin{array}{l}\text { carbonato e } \\
\text { sulfato }\end{array}$} & $4,95 \mathrm{a}$ & $0,12 \mathrm{~d} \quad 3,58 \mathrm{a}$ & $1,41 \mathrm{ab}$ & $1,10 \mathrm{a}$ & $4,78 \mathrm{bc}$ \\
\hline & \multicolumn{5}{|c|}{ LV sob floresta } \\
\hline testemunha & $4,62 d$ & $0,30 \mathrm{a} \quad 2,77 \mathrm{c}$ & $0,61 d$ & $0,15 \mathrm{c}$ & $5,05 a b$ \\
\hline $\begin{array}{l}\text { carbonato } \\
\text { isolado }\end{array}$ & $4,92 a b$ & $0,20 \mathrm{c} \quad 2,89 \mathrm{c}$ & $0,90 \mathrm{c}$ & $0,55 \mathrm{~b}$ & $5,04 a b$ \\
\hline $\begin{array}{l}\text { sulfato } \\
\text { isolado }\end{array}$ & $4,75 \mathrm{c}$ & $0,30 a \quad 3,69 a$ & $1,48 \mathrm{a}$ & $1,08 \mathrm{a}$ & $4,55 \mathrm{c}$ \\
\hline $\begin{array}{l}\text { carbonato e } \\
\text { sulfato }\end{array}$ & $5,16 a$ & $0,15 d \quad 3,31 b$ & $1,29 \mathrm{~b}$ & $1,05 \mathrm{a}$ & $4,72 \mathrm{c}$ \\
\hline
\end{tabular}

${ }^{(1)}$ médias seguidas de mesma letra, dentro da mesma coluna, não diferem pelo teste de Duncan a $5 \%$.
O abaixamento do PESN na subsuperfície confirma a geração de novos sítios de adsorção de cátions com a aplicação de sulfato de cálcio, isoladamente ou em mistura com o carbonato de cálcio (TABELA 3). Observase, ainda, que na superfície a aplicação de sulfato de cálcio promoveu diminuições nos teores de alumínio trocável (TABELA 2), não afetando, entretanto, o teor de alumínio trocável na subsuperfície (TABELA 3), embora em ambas as profundidades este tratamento tenha sido efetivo em promover aumentos no teor de cálcio trocável (Wadt, 1991). Portanto, parece provável que a "adsorção salina", ao menos nas amostras de solo deste estudo, poderia ser atribuída à adsorção de sulfato na camada de Stern, conforme mecanismo sugerido por Marsh et al. (1987), e não somente por ligações de caracter iônico, conforme proposto por Pearce \& Sumner (1997).

Na presença de carbonato de cálcio, as diminuições nos teores de alumínio trocável estiveram relacionadas à neutralização da acidez do solo. No entanto, na ausência da aplicação de carbonato de cálcio as diminuições nos teores de alumínio trocável, não podem ser atribuídas às reações de neutralização da acidez do solo.

Assim, têm-se dois efeitos distintos no que se refere aos tratamentos com aplicação de sulfato de cálcio:

a) na superfície, onde houve predominantemente diminuição do teor de alumínio trocável, sem haver a geração de novos sítios de adsorção e;

b) na subsuperfície, onde houve predominantemente a geração de novos sítios de adsorção, sem haver diminuições no teor de alumínio trocável.

$\mathrm{Na}$ subsuperfície, onde as propriedades eletroquímicas dos minerais de argila predominam sobre as propriedades dos colóides orgânicos, a reação predominante do sulfato deslocado da superfície para a subsuperfície foi provavelmente a sua adsorção química na superfície dos óxidos presentes no solo, concordando com resultados de Lobo (1986). A adsorção específica do ânion sulfato, ao transferir sua carga à superfície adsorvente, geraria novos sítios para adsorção de cátions, promovendo assim os aumentos observados na CTC (a $\mathrm{pH} 7,0)$ e CTC efetiva, e o abaixamento do PESN.

Com efeito, os aumentos nos teores de cálcio trocável na subsuperfície, nos tratamentos com aplicação isolada de sulfato de cálcio, deram-se independentemente da neutralização do alumínio trocável, dependendo praticamente, apenas da geração de novos sítios de adsorção (TABELA 3).

Além disto, no tratamento com a mistura das duas fontes de cálcio, a provável presença de bicarbonato na solução percolada da superfície para a subsuperfície poderia ter dificultado a adsorção do ânion sulfato, à vista do baixo valor do PESN e menores aumentos na CTC e CTC efetiva. Bolan et al. (1988) observaram que a incubação de solos com carbonato de cálcio promoveu aumentos nas cargas negativas e pequenas reduções nas cargas positivas, diminuindo, no entanto, o número de sítios para adsorção de sulfato. O bicarbonato, deslocado 
da superfície para a subsuperfície, poderia causar efeitos semelhantes ao aumentar a eletronegatividade das superfícies adsorventes através da dessorção de prótons e assim, diminuir a adsorção do sulfato.

Embora a superfície apresente basicamente a mesma mineralogia ${ }^{4}$ da subsuperfície, com predomínio de caulinita e traços de gibbisita (Wadt, 1991), na superfície, devido ao seu maior teor de carbono orgânico, os colóides minerais provavelmente encontram-se revestidos por substâncias húmicas (Stevenson, 1982), onde cátions metálicos e hidrogênio fazem a ponte entre os grupamentos acídicos do húmus e os sítios de adsorção catiônica dos minerais de argila. Spark et al. (1997) encontraram que a adsorção de ácido húmico esteve relacionada com a natureza das cargas de superfície de minerais como goetita, alfa-alumina, caulinita e silicatos: superfície carregadas positivamente absorveram ácidos húmicos a uma maior proporção que aquelas carregadas negativamente, sendo que o primeiro processo envolvia o consumo de prótons, o que não foi observado no segundo processo.

Portanto, superfícies de óxidos carregadas positivamente podem também estar revestidas por substâncias orgânicas. Disto resulta que a superfície adsorvente dos colóides nas amostras superficiais ser mais eletronegativa que a superfície adsorvente dos colóides nas amostras subsuperficiais, conforme pode ser inferido pelos valores de PESN das suas respectivas testemunhas (TABELAS 2 e 3). Neste ambiente (superfície), a adsorção do ânion sulfato seria dificultada. Marsh et al. (1987) notaram que há pouca ou nenhuma adsorção de sulfato na ausência de sítios de carga positiva, indicando ser o sulfato adsorvido pelos sítios de carga positiva. Além disto, COD também compete com sulfato pelos sítios de adsorção do solo (Nodvin et al., 1986a), sendo que em horizontes onde há maior teor de matéria orgânica, a competição torna-se mais efetiva. Disto resulta que a concentração iônica dos ânions sulfato na nuvem de contra-íons em torno destas superfícies adsorventes também será afetada.

Conseqüentemente, parte dos ânions sulfato oriundos da solubilização do sulfato de cálcio adicionado, não podendo ser adsorvidos, poderiam ser desviados para outras reações, dentre estas aquelas relacionadas à precipitação do alumínio deslocado do complexo de troca pelo aumento da atividade dos íons cálcio no sistema, levando à formação de minerais do tipo da alunita e basuluminita, conforme proposto por Reeve \& Sumner (1972), Pavan et al. (1984), Sumner et al. (1986), ou jurbanita (Menzier et al., 1994).

Assim, dependendo das características eletroquímicas dos colóides existentes no solo, haveria favorecimento para a adsorção do sulfato nas superfícies minerais ou para reações envolvendo a precipitação e ou fixação dos polímeros de alumínio por ventura presentes.
Na superfície, devido a abundância de colóides orgânicos, a reação predominante poderia seguir a rota proposta por Saigussa \& Toma (1997), onde o alumínio deslocado do complexo de troca seria fixado irreversivelmente e seletivamente após sua polimerização na solução do solo. Nesta camada, poderia, ainda, haver a precipitação do alumínio com o sulfato presente na solução do solo. Este segundo processo é reforçado pelo fato de terem sido encontradas menores proporções de alumínio no percolado, nos tratamentos com adição de sulfato de cálcio (Wadt, 1991), enquanto que naqueles com adição de carbonato de cálcio, houve maiores quantidades de aluminio no percolado, provavelmente, em decorrência da solubilização da matéria orgânica, pelo aumento do pH, o que dificultaria a precipitação do alumínio (Singer \& Huang, 1990).

Na subsuperfície, onde não se observou a redução do $\mathrm{Al}^{3+}$ trocável, teria ocorrido a adsorção de sulfato na camada de Stern e o aumento da CTC efetiva, mantendose os mesmos níveis de Al na fase trocável. Esta dedução é reforçada com base nos resultados de Bolan et al. (1993), que encontraram maior adsorção de sulfato com o aumento da adsorção de cálcio, cuja magnitude do fenômeno foi 12 vezes maior em solos contendo óxidoshidróxidos de $\mathrm{Fe}$ e Al como os principais constituintes da carga variável, em comparação com os solos cuja carga variável era determinada principalmente pela matéria orgânica.

Estes dois processos representam, pois, os principais mecanismos capazes de remover o ânion sulfato da fase aquosa e, portanto, de afetar a mobilidade dos cátions acompanhantes. A mobilidade dos cátions acompanhantes do ânion sulfato pode ser aumentada, portanto, através de mecanismos que aumentem a eletronegatividade das superfícies adsorventes, como a adsorção específica de fosfato (Bolan et al., 1988), da elevação do pH do solo (Korentajer et al., 1983) ou da diminuição da disponibilidade de íons alumínio livre.

\section{CONCLUSÕES}

- Os estudos dos processos envolvendo o sulfato no solo, sejam reações de adsorção, sejam de precipitação, devem necessariamente considerar a interação da matéria orgânica com os colóides do solo.

- Havendo predomínio de superfícies com potencial eletropositivo, o sulfato tende a ser preferencialmente adsorvido por estas superfícies; Havendo predomínio de superfícies com potencial eletronegativo e elevados teores de alumínio trocável, a principal reação do sulfato passa a ser de precipitação com o alumínio.

- O efeito da aplicação de gesso nas propriedades químicas do solo depende fundamentalmente das características eletroquímicas desses solos.

${ }^{4}$ Solos predominantente cauliníticos, com traços de goetita e gibbsita. 


\section{REFERÊNCIAS BIBLIOGRÁFICAS}

ADAMS, F.; RAWAJFIH, B.F. Basalunita and alunita: a possible cause of sulfate retention by acid soils. Soil Science Society of America Journal, v.41, p.686-692, 1977.

BOLAN, N.S.; SCOTTER, D.R.; SYERS, J.K.; TILLMAN, R.W. The effect of adsortion on sulfate leaching. Soil Science Society of America Journal, v.50, p.1419-1424,1986.

BOLAN, N.S.; SYERS, J.K.; TILLMAN, R.W.; SCOTTER, D.R. Effect of liming and phosphate additions on sulphate leaching in soils. Journal of Soil Science, v.39, p.493-504, 1988.

BOLAN, N.S.; SYERS, J.K.; SUMNER, M.E. Calcium-induced sulfate adsorption by soils. Soil Science Society of America Journal, v.57, p.691-696, 1993.

CHAVES, J.C.D.; PAVAN, M.A.; MYASAWA, M. Redução da acidez subsuperficial em coluna de solo. Pesquisa Agropecuária Brasileira, v.23, p.469-476, 1988.

CURTIN, D.: SYERS, J.K. Mechanism of sulphate adsorption by two tropical soils. Journal of Soil Science, v.41, p.295-304, 1990.

Empresa Brasileira de Pesquisa Agropecuária. Manual de métodos de análise de solo. Rio de Janeiro: Serviço Nacional de Levantamento e Conservação de Solos,1979. $1 \mathrm{v}$.

EVANS JUNIOR, A.; ZELAZNY, L.W. Effects of sulfate additions on the exchangeable aluminum in a Cecil soil. Soil Science, v.143, p.410-417, 1987.

KORENTAJER, L.; BYERNES, B.H.; HELLMS, D.T. The effects of liming and leaching on the surfur-supplying capacity of soils. Soil Science Society of America Journal, v.47, p.525-529, 1983.

LOBO, I. Eletroquímica de latossolos: efeitos da adsorção de ânions e cátions. Itaguai, 1986. 137p. Dissertação (Mestrado) - Universidade Federal Rural do Rio de Janeiro.

MARSH, K.B.; TILLMAN, R.W.; SYERS, J.K. Charge relationships of sulfate sorption by soils. Soil Science Society of America Journal, v.51, p.318-323, 1987.

MENZIER, N.W.; BELL, L.C.; EDWARDS, D.G. Exchangeable and solution phase chemistry of acid, highly weathered soils. II. Investigation of mechanism controlling Al release into solution. Australian Journal of Soil Research, v.32, p.269-283, 1994.

MOTAVALLI, P.P.; DUXBURY, J.M.; SOUZA, D.M.G. The influence of organic soil amendments on sulfate adsorption and surfur availability in a Brazilian oxisol. Plant and Soil, v.154, p.301-308, 1993.

NODVIN, S.C.; DRISCOLL, C.T.; LIKENS, G.E. Simple partitioning of anions and dissolved organic carbon in a forest soil. Soil Science, v.142, p.27-35, 1986a.

NODVIN, S.C.; DRISCOLL, C.T.; LIKENS, G.E. The effects of $\mathrm{pH}$ on surface adsorption by a forest soil. Soil Science, v.142, p.69-75,1986b.
PAVAN, M.A.; BINGHAM, F.T.; PRATT, P.F. Redistribution of exchangeable calcium, magnesium, and aluminum following lime or gypsum applications to a Brasilian oxisol. Soil Science Society of America Journal, v.48, p.33-38, 1984.

PEARCE, R.C.; SUMNER, M.E. Apparent salt sorption reactions in a unfertilized acid subsoil. Soil Science Society of America Journal, v.61, p.765-772, 1997.

RAIJ, B. van; QUAGGIO, J.A.; CANTARELLA, H.; FERREIRA, M.E.; LOPES, A.S.; BATAGLIA, O.C. Análise química do solo para fins de fertilidade. Campinas: Fundação Cargill, 1987. 170p.

REEVE, N.G.; SUMNER, M.E. Amelioration of subsoil acidity in Natal oxisols by leaching of surface-applied amendments. Agrochemophysica, v.4, p.1-5, 1972.

RITCHEY, K.D.; SOUZA, D.M.G.; LOBATO, E.; CORREA, O. Calcium leaching to increase rooting depth in a brasilian savannah oxisol. Agronomy Journal, v.72, p.40-42, 1980.

SAIGUSSA, M.; TOMA, M. Mechanism of reduction of exchangeable aluminium by gypsum application in acid andosols. Soil Science and Plant Nutrition, v.43, p.343-349, 1997.

SINGER, A.; HUANG, P.M. Effects of humic acid on the crystallization of aluminium hydroxides. Clays and Clays Minerals, v.38, p.47-52, 1990.

SPARK, K.M.; WELL, J.D.; JOHNSON, B.B. Characteristics of the sorption of humic acid by soil minerals. Australian Journal of Soil Research, v.35, p.103-112, 1997.

STEVENSON, F.J. Humus Chemistry, genesis, composition, reactions. New York: John Wiley \& Sons, 1982. 443p.

SUMNER, M.E.; SHAHADNDEH, H.; BOUTON, J.; HAMMEL, J. Amelioration ofan acid soil profile through deep liming and surface application of gypsum. Soil Science Society of America Journal, v.50, p.1254-1258, 1986.

UEHARA, G.; GILLMAN, G.P. The mineralogy, chemistry and physics of tropical soils with variable charge clays. Colorado: Westview Press, 1981.170p.

WADT, P.G.S. Movimentação de cátions em Latossolo VermelhoAmarelo, álico, incubado com carbonato e sulfato de cálcio, isolados ou misturados. Itaguai, 1991. 174p. Dissertação (Mestrado) - Universidade Federal Rural do Rio de Janeiro.

WADT, P.G.S.; SANTOS, G. A.; MARTINS, C; LEAL, J.R. Determinação do ponto de efeito salino nulo por meio de regressão linear simples. In: Congresso Brasileiro de Ciência do Solo, 25., Viçosa, 1995. Anais. Viçosa: SBCS/UFV, 1995. p.286-288

YAMADA, T. Capacidade de adsorção máxima de sulfato do solo como parâmetro adicional na recomendação de gesso. Piracicaba, 1988. 73p. Tese (Doutorado) - Escola Superior de Agricultura "Luiz de Queiroz", Universidade de São Paulo.

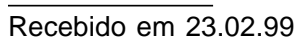

